\title{
A REVIEW: A GREEN APPROACH FOR THE SYNTHESIS OF SILVER NANOPARTICLES AND ITS ANTIBACTERIAL APPLICATIONS
}

\author{
SHYLA MARJORIE HAQQ, AMIT CHATTREE \\ Department of Chemistry, SamHigginbottom University of Agriculture, Technology and Sciences, Allahabad - 211 007, Uttar Pradesh, \\ India. Email: shylahaqq3@gmail.com
}

Received: 19 January 2018, Revised and Accepted: 17 May 2018

\begin{abstract}
This review is based on the synthesis of silver nanoparticles (AgNPs) using a green approach which is biofabricated from various medicinal plants. AgNPs were prepared from the various parts of the plants such as the flowers, stems, leaves, and fruits. Various physiochemical characterizations were performed using the ultraviolet (UV)-visible spectroscopy, Fourier transform infrared spectroscopy, X-ray diffraction spectroscopy, transmission electron microscopy, and energy dispersive spectroscopy. AgNPs were also used to inhibit the growth of bacterial pathogens and were found to be effective against both the Gram-positive and Gram-negative bacteria. For the silver to have antimicrobial properties, it must be present in the ionized form. All the forms of silver-containing compounds with the observed antimicrobial properties are in one way or another source of silver ions. Although the antimicrobial properties of silver have been known, it is thought that the silver atoms bind to the thiol groups in enzymes and subsequently leads to the deactivation of enzymes. For the silver to have antimicrobial properties, it must be present in the ionized form. The study suggested that the action of the AgNPs on the microbial cells resulted into cell lysis and DNA damage. AgNPs have proved their candidature as a potential antibacterial against the multidrug-resistant microbes. The biological agents for synthesizing AgNPs cover compounds produced naturally in microbes and plants. Reaction parameters under which the AgNPs were being synthesized hold prominent impact on their size, shape, and application. Silver nanoparticle synthesis and their application are summarized and critically discussed in this review.
\end{abstract}

Keywords: Antimicrobial activity, Ultraviolet-visible spectroscopy, Fourier transform infrared spectroscopy, X-ray diffraction spectroscopy, Scanning electron microscopy, Energy dispersive spectroscopy, High-resolution transmission electron microscopy.

(C) 2018 The Authors. Published by Innovare Academic Sciences Pvt Ltd. This is an open access article under the CC BY license (http://creativecommons. org/licenses/by/4. 0/) DOI: http://dx.doi.org/10.22159/ajpcr.2018.v11i8.26767

\section{INTRODUCTION}

Nanotechnology may be defined as a modern research which deals with the synthesis, design, and manipulation of the particle size ranging from 1 to $100 \mathrm{~nm}$. Nanotechnology is the study of small objects which can be used across all the branches such as chemistry, biology, physics, material science, and engineering. They are used for coating medical tools and materials used in the area of surgery, cardiology, and urology [1]. Nanotechnology is on the threshold of providing a host of new materials and approaches in revolutionizing the medical and pharmaceutical field. It is rapidly growing by the production of the nanoproducts and the nanoparticles that can have novel and size related physicochemical properties differing significantly from the large matter. Among all the noble metal nanoparticles it is the AgNPs which are arch product in the field of nanotechnology as it has gained boundless interest because of their unique properties such as the chemical stability, good conductivity, antiviral, antifungal, and antiinflammatory activities [2]. They have attracted a great deal of attention due to their unique physical, chemical, optical, and biological properties and have also found tremendous application in the field of biomedicine, drug delivery, topical ointments, creams, food industry, textile treatment, and water industry [3]. In general, there are two approaches which are involved in the synthesis of nanoparticles either from top to bottom approach or a bottom to top approach. In the case of bottom to top approach, nanoparticles can be synthesized using the chemical and biological method by self-assemble of atoms to new nuclei which grow into a particle of nanoscale while in top to bottom approach suitable bulk material breakdown into the fine particles by the size reduction with the various lithographic techniques. According to the literature survey it has been found that the biological synthesis of AgNPs using the microorganisms includes bacteria, fungi, and plants. The use of the plant extracts for this purpose is advantageous over the other microorganisms due to the ease of improvement, the less biohazard and the elaborate process of maintaining the cell cultures [4]. Greener synthesis of nanoparticles also provides advancements over other methods as they are simple, one step, cost-effective, environment-friendly, and relatively reproducible and often results in more stable materials [5]. Nano AgNPs were synthesized using Azadirachta indica aqueous leaf extract where the nanoparticles were found to be predominantly spherical in shape [6]. Colloidal silver is of particular interest because of distinctive properties such as good conductivity, chemical stability, catalytic, and antibacterial activities. The use of medicinal plant parts such as the stem, seed, and bark for the synthesis of AgNPs is a quite novel method leading to green chemistry in comparison to other methods such as the chemical and physical methods [7]. Plant extracts have been used as a reducing, capping and stabilizing agents for the synthesis of AgNPs due to their reducing properties [8]. Nanomaterials can provide solutions to many technological and environmental challenges in the field of solar energy conversion, medicine, and wastewater treatment [9]. Over the past few decades, there has been an increased emphasis on the synthesis of metal nanoparticles and quantum dots [10].

\section{Physiochemical characterization of AgNPs}

UV visible spectroscopy

The synthesis of AgNPs using Albizia lebbeck (L) Benth extract has been confirmed by the UV-visible spectrum. Longitudinal vibrations corresponding to the AgNPs were found to have UV-spectral peak at $407 \mathrm{~nm}$. This clearly indicated the interaction between the Ag+ ions and phytochemical present in the methanolic extract. Intensity of the band increased on varying time without any shift in the peak position [11]. The synthesis of AgNPs had been confirmed by measuring the UVvisible spectrum of colloidal solutions of AgNPs which are been synthesized from Boswellia ovaliofoliolata, Shorea tumuggaia, and Svensonia hyderobadensis were found to have an absorbance peak at $350 \mathrm{~nm}, 430 \mathrm{~nm}$, and 300-400 nm, respectively, and the broadening 
of the peak indicated that the particles are polydispersed [12]. AgNPs were synthesized at different concentrations of $A$. indica aqueous leaf extract such as 1-5 ml using $1 \mathrm{mM}$ of silver nitrate which were analyzed by the UV spectra of plasmon resonance band observed at 436-446nm which is similar to those reported in the literature [13]. On synthesizing the AgNPs using the banana peel extract, an absorbance of $433 \mathrm{~nm}$ was observed [14]. During the synthesis of AgNPs using the seed extract of Alpinia katsumadai, the absorbance band was observed at $417 \mathrm{~nm}$ which was slightly shifted to $436 \mathrm{~nm}$. This shift may be attributed due to the aggregation of the smaller particles according to the Mie theory [15]. The synthesized AgNPs exhibit lowest absorption band at $400 \mathrm{~nm}$ [16]. AgNPs were also synthesized using the extract of saffron (Crocus sativus L). The synthesized AgNPs were determined by UV-visible spectrum. The UV-visible spectrum showed a peak at $450 \mathrm{~nm}$ due to the excitation of surface plasmon vibrations. The peak indicated the reduction of silver nitrate into AgNPs [17]. The present research work describes the synthesis of AgNPs using the ethanolic leaf extract of Curvibacter lanceolatus, Dracocephalum parviflorum, Eucalyptus citriodora, Melaleuca cajuputi, Rhodomyrtus tomentosa, Syzygium campanulatum, and Xanthostemon chrysanthus where the SPR band appeared at 420, 417, 418, 458, 434, 462, and $424 \mathrm{~nm}$, respectively. It is known that the SPR band is sensitive to the discrete dipole approximation considering different shapes and sizes of the particles formed [18]. Similar results were observed on the synthesis of AgNPs using the leaf extract of Datura stramonium where it was found that a narrow SPR peak appeared at $444 \mathrm{~nm}$ which may be ascribed to the formation of isotropic spherical AgNPs. This adequate reducing biomolecules within the leaf extract greatly reduced the silver nitrate solution as silver crystal and wrapped around the AgNPs [19].

\section{FTIR spectroscopy}

The FTIR spectroscopy of the synthesized AgNPs using the flower extract of Hibiscus rosa sinensis showed the peak at $3403 / \mathrm{cm}$, $2928 / \mathrm{cm}, 2355 / \mathrm{cm}$, and $670 / \mathrm{cm}$ which indicates the functional groups of the plant component that is involved in the reduction and stabilization of the AgNPs. This attributes to the $\mathrm{OH}$ stretch, $\mathrm{C}=\mathrm{C}$ bond and $\mathrm{C}-\mathrm{H}$ that reveals the water-soluble heterocyclic components, polyols, and certain proteins present in the extract [20]. FTIR analysis was done to identify the possible biomolecules in case of synthesis of marigold flower where the band at $3740.10 / \mathrm{cmcorresponds}$ to the $\mathrm{N}-\mathrm{H}$ amide stretching. The peak at $727.19 / \mathrm{cmcorresponds}$ to the C-H stretching. The peak at $793.73 / \mathrm{cm}$ corresponds to the $\mathrm{C}-\mathrm{Cl}$ stretching alkyl halides and $693.43 / \mathrm{cm}$ corresponds to the $\mathrm{C}-\mathrm{H}$ stretching strong vinyl disubstituted alkenes [21]. The FTIR analysis of Plumeria leaves indicated the possible biomolecules that were responsible for the reduction of Ag+ions and the capping of the reduced AgNPs synthesized using Plumeria leave extract. Strong IR bands were observed at 3703/ $\mathrm{cm}$ and $2922 / \mathrm{cm}$ which corresponded to the $\mathrm{N}-\mathrm{H}, \mathrm{OH}$ stretching, and aliphatic $\mathrm{CH}$ stretching. The bands at 2333 and $1618 / \mathrm{cm}$ are due to the $\mathrm{CO}_{2}$ and $\mathrm{C}=\mathrm{C}$, respectively [22]. The FTIR spectra of synthesized silver nanoparticle using Cassia fistula leaf extract showed the peaks at $3403 / \mathrm{cm}, 2928 / \mathrm{cm}, 2355 / \mathrm{cm}$, and $670 / \mathrm{cm}$ which indicated the functional group of the component that is involved in the reduction and stabilization of AgNPs [23]. To study the formation of the AgNPs using B. globose extract, the FTIR measurements were performed. This measurement confirms the presence of some functional groups capping the AgNPs. Three main peaks were observed at $3464 / \mathrm{cm}$, $2083 / \mathrm{cm}$, and $1636 / \mathrm{cm}$. The broadband around $3464 / \mathrm{cm}$ was due to the $\mathrm{OH}$ stretching vibrations of phenols and carboxylic groups present in the extract. The absorbance band at $2083 / \mathrm{cm}$ corresponds to the alkyne groups of phytoconstituents of the extract and the band at $1636 / \mathrm{cm}$ can be associated to $\mathrm{C}=0$ stretching vibrations. The results were found to be similar to the other AgNPs synthesized by the different plant extract [24]. The FTIR spectra of the AgNPs which were synthesized using cannonball leaves exhibited prominent peaks at $2927 / \mathrm{cm}, 1631 / \mathrm{cm}$, and $1383 / \mathrm{cm}$. The spectra showed sharp and strong absorption band at $1631 / \mathrm{cm}$ which is assigned to the stretching vibration of (NH) C=0 group. The band at $1383 / \mathrm{cm}$ was developed for
C-C and C-N stretching. The presence of a sharp peak at 2927/cm was assigned to C-H (methoxy compounds) stretching vibration [25].

\section{TEM image}

The shape and size of the resultant particles which were synthesized using Pedalium murex leaf extract were found to be around $50 \mathrm{~nm}$. The particles were found to be spherical in shape [26]. Tem analysis revealed that the synthesized nanoparticles using the Morinda Pubescens showed that the synthesized nanoparticles were stable in the solution and the size of the nanoparticles ranged from 20 to $40 \mathrm{~nm}$ [27]. The Tem image of the synthesized AgNPs using Calotropis procera latex showed that the particles were spherical in shape, well dispersed with a diameter range from $4 \mathrm{~nm}$ up to $25 \mathrm{~nm}$ and an average particle size of $12.33 \mathrm{~nm}$ [28]. The Tem image of the synthesized AgNPs from the Chrysanthemum indicum extract showed the particle size to be $37.71-71.99 \mathrm{~nm}$ where they had a smooth surface and polydispersed particles [29]. On the synthesis of AgNPs using Parkia speciosa Hassk pods by the Tem images, it was reported that the size of the nanoparticle was coming to be around $20-50 \mathrm{~nm}$. This Tem image exhibited the mixture of shapes with mainly spherical shapes as predominant [30]. The result indicated that the average particle size of the synthesized AgNPs using olive leaf extract showed the size to be around $30 \pm 6 \mathrm{~nm}$ at the lower extract concentration and, on the other hand, at the higher concentration the majority of the AgNPs were found to be in the range of 8-15 nm. Similar studies showed that a comparatively higher extract ratio is responsible for the synthesis of symmetrical nanoparticles [31].

\section{$X$-ray diffraction $(X R D)$ spectroscopy}

The XRD analysis revealed the patterns at $2 \theta=32.4^{\circ}, 46.4^{\circ}$, and $28.0^{\circ}$ during the synthesis of the AgNPs using leaf extract of Catharanthus roseus Linn G. These Braggs reflections clearly indicated the presence of (111), $(2,0,0)$ and $(3,1,1)$ sets of the lattice planes and further on the basis they can be indexed as face-centered cubic structure of silver. Hence, the XRD pattern clearly illustrates that the AgNPs formed in the present synthesis are crystalline in nature [32]. The crystalline nature of the biosynthesized AgNPs using the Eriobotrya Japonica leaf extract was confirmed by the XRD pattern. The diffraction peaks at $2 \theta$ values of $38.11^{\circ}, 44,64^{\circ}$ and $77^{\circ}$ corresponded to the $111,200,220$, and 311 crystallographic planes. The unsigned peaks may be associated with the organic compounds which originated from the E. japonica leaf extract and function as reductants and stabilizers for AgNPs in the mixture [33]. The exact nature of synthesized that silver nanoparticle using Ananas comosus formed can be deduced from the XRD spectrum. The XRD pattern of the plant-derived AgNPs showed four intense peaks in the whole spectrum of $2 \theta$ values which range from $20^{\circ}$ to $80^{\circ}$. The XRD spectrum of the AgNPs formed in our experiments at $2 \theta$ values of $38.45^{\circ}, 44.48^{\circ}, 64.69^{\circ}$, and $77.62^{\circ}$ corresponding to $(1,1,1),(2,0,0)$, $(2,2,0)$, and $(3,1,1)$ planes for silver [34]. The green synthesized AgNPs from the fruit extract of Cleome viscosa $L$ showed the $2 \theta$ angles at the range of $38.68^{\circ}, 44.1^{\circ}, 64.11^{\circ}$, and $77.4^{\circ}$ which corresponded to the 111 , 200,220 , and 222 planes that confirmed the formation of face-centered cubic silver crystal [35]. The XRD pattern of the Ricinus communis var carmencita leaf extract showed the presence of Braggs peak at $2 \theta$ values, i.e., $27.81^{\circ}, 32.19^{\circ}, 38.16^{\circ}, 44.43^{\circ}, 46.23^{\circ}, 54.93^{\circ}, 57.39^{\circ}, 64.65^{\circ}$, and $77.61^{\circ}$ which corresponded to $(2,1,0),(1,2,2),(1,1,1),(2,0,0),(2,3,1)$, $(1,4,2),(2,4,1),(2,2,0)$, and $(3,1,1)$ plane of the silver metals which are on the faced-centered cubic structure. Thus, the XRD studies confirmed the crystallinity of Ricinus communis var carmencita AgNPs [36]. The pattern clearly showed the main peaks at $2 \theta=38.190,44.37^{\circ}, 64.56^{\circ}$, and $77.47^{\circ}$ which corresponded to the $(1,1,1),(2,0,0),(2,2,0)$, and $(3,1,1)$ planes. The green synthesized AgNPs using pedalium murex leaf extract is found to possess an fcc structure. By determining the width of 1,1,1 Braggs reflection the estimated average size of the particle was found to be $14 \mathrm{~nm}$ [26]. The XRD analysis was carried out to confirm the crystalline nature of the AgNPs synthesized using Brassicaceae members. The XRD spectra scanned over a $2 \theta$ range of $20^{\circ}-80^{\circ}$ showed the Braggs angle at $37.9^{\circ}, 46.2^{\circ}, 64.3^{\circ}$, and $76.6^{\circ}$ which corresponded to (111), (200), (220), and (311) crystal reflection planes of the four 
Table 1: AgNPs synthesized from various plant extracts

\begin{tabular}{lll}
\hline Plant & Plant part used & $\begin{array}{l}\text { Particle size } \\
\text { (nm) }\end{array}$ \\
\hline Azadirachta indica & Leaf & $34 \mathrm{~nm}$ \\
Plumeria rubra & Flower & $20-80 \mathrm{~nm}$ \\
Marigold & Flower & $46.11 \mathrm{~nm}$ \\
Orange peel extract & Peel & $7.36 \pm 8.06 \mathrm{~nm}$ \\
Calotropis procera & Flower & $37 \mathrm{~nm}$ \\
Olive & Leaf & $20-25 \mathrm{~nm}$ \\
Carob & Leaf & $5-40 \mathrm{~nm}$ \\
Andean blackberry & Fruit & $12-50 \mathrm{~nm}$ \\
Morus nigra & Leaf & $4-8 \mathrm{~nm}$ \\
Spinacia oleracea & Leaf & $10 \mathrm{~nm}$ \\
Musa balbisiana & Leaf & $200 \mathrm{~nm}$ \\
Azadirachta indica & Leaf & $200 \mathrm{~nm}$ \\
Ocimum & Leaf & $3-20 \mathrm{~nm}$ \\
Cassia fistula & Leaf & $50 \mathrm{~nm}$ \\
Buddleja & Leaf & $20 \mathrm{~nm}$ \\
Ocimum sanctum & Leaf & $14.6 \mathrm{~nm}$ and \\
& & $11.35 \mathrm{~nm}$ \\
Apple extract & Fruit & $30.25 \pm 5.26 \mathrm{~nm}$ \\
\hline
\end{tabular}

AgNPs: Silver nanoparticles

faces of the face-centered cubic crystalline structure of the AgNPs. The observed results were found to be in agreement with the JCPDS No-652871. Reflection planes 111 and 200 were the predominant orientations while the reflections of 220 and 311 were weak and broad. The results confirmed the formation of fcc crystalline AgNPs by the reduction of Ag ions by the aqueous B. oleracea var botrytis and radish extracts [37].

\section{EDS spectroscopy}

The elemental analysis was performed to confirm the presence of silver nanoparticles in the solution. The EDS analysis of $S$. officinarium mediated synthesis of AgNPs showed an intense signal at $3 \mathrm{keV}$ which indicates the presence of elemental silver [38]. The EDS analysis of the synthesized AgNPs using Exiguobacterium mexicanum confirmed that the sample contained predominantly silver. The sample has other elements such as silicon, oxygen, phosphorus, chlorine, and calcium. The other elements phosphorus, calcium, chlorine, and silicon identified in EDS indicated the presence of a biological matrix present in the sample [39]. The existence of the silver element in the AgNPs which were synthesized by Bacillus amyloliquefaciens and Bacillus subtilis to control filarial vector Culex pipiens pallens was confirmed by the EDX instrument. This indicated the formation of the AgNPs in cell-free supernatant from bacteria D29 and A15 where the strong peak of silver ions was observed at $3 \mathrm{keV}$ which confirmed the reduction of silver ions $\mathrm{Ag}+$ in to $\mathrm{Ag}^{\circ}$ [40]. The AgNPs were synthesized using three medicinal plants Musa balbisiana, A. indica, and Ocimum tenuiflorum. The EDS profile showed a strong silver signal along with weak oxygen and carbon peaks, which may have originated from the biomolecules that were bound to the surface of the AgNPs. Carbon and copper peaks may be due to the same being present in the grids. It has been reported that the nanoparticles synthesized using plant extracts are surrounded by a thin layer of some capping organic material from the plant leaf broth. This is another advantage of nanoparticles synthesized using plant extracts over those synthesized using chemical methods [41]. In a simple reported that the AgNPs were synthesized using the leaf extract of Aegle marmelos and found that the EDX spectrum showed a peak of silver which confirmed its presence in the suspension. Other peaks may be due to the attached groups from the leaf extracts on the surface of the nanoparticles [42]. The AgNPs were synthesized using Brassica oleracea var Botrytis and found that the EDAX spectrum of the solution containing AgNPs was observed at $3 \mathrm{KeV}$, which is typical for the absorption of the metallic nanoparticles [43].

\section{Antibacterial activity of AgNPs}

The AgNPs have potent antibacterial action against both the Grampositive and Gram-negative bacteria. There are contradictory reports regarding antibacterial action against Gram-positive and Gramnegative bacteria. According to some researchers, the Gram-negative bacteria are reported to be more sensitive to AgNPs compared to the Gram-positive bacteria whereas reverse results were observed by the other researchers. The antibacterial property of the AgNPs may be due to their interactions with the cell wall of the bacteria that result in the pore formation in the cell walls where the AgNPs get deposited that causes change in the permeability of the cell membrane. The reported differential sensitivity of both the bacterial species could be attributed to the difference in the structural characteristics of the bacterial species as well as the shape and size of the silver nanoparticle, bacterial inoculum, size, exposure time, and nutrient medium used during analysis of antibacterial action [44]. In the ionized form silver is inert, but on coming in contact with the moisture, it releases silver ions. The nanoparticles have been shown to accumulate inside the membrane and can subsequently penetrate into the cells thereby leading to damage of the cell wall and cell membrane. It is thought that silver atoms bind to the thiol group of enzymes forming the stable S-Ag bonds with the thiolcontaining compounds which cause the deactivation of enzymes in the cell membrane [45]. The advantage of AgNPs is that they are known to have an antibacterial effect. AgNPs were studied for their bactericidal effect against both the Gram-positive bacteria, i.e., S. epidermidis and Gram-negative bacteria P. aeroginosa [46]. The synthesized AgNPs were tested against the vector mosquitoes of A. Stephensi, A aegypti, and $C$. quinquefasciatus where the result suggested that the use of S. acuta synthesized AgNPs can be a rapid, environmentally safer biopesticide that can form a novel approach to develop the effective biocides for controlling the target vector mosquitoes. This is the first report on the mosquito larvicidal activity of the plant aqueous extract and the synthesized nanoparticles [47]. The antimicrobial activity of Glycyrrhiza glabra AgNPs was analyzed for the first time against Pseudomonas aeruginosa, Staphylococcus aureus, Escherichia coli, Bacillus spp., Salmonella spp., Trichoderma spp., Candida albicans, and Rhizopus spp. using the disc diffusion method. The culture plates were treated with G. glabra AgNPs thereby exhibiting the significant antimicrobial activity of $1.2 \mathrm{~cm}-1.1 \mathrm{~cm}$ zone of inhibition to $S$. aureus and $P$. aeruginosa, respectively, which was nearby comparable to the standard antibiotic and also was found to inhibit other bacteria [48]. The existence of the silver element in the AgNPs which were synthesized by Bacillus amyloliquefaciens and Bacillus subtilis to control filarial vector C. pipiens pallens was confirmed by the EDX instrument. This indicated the formation of the AgNPs in cell-free supernatant from bacteria D29 and A15 where the strong peak of silver ions was observed at $3 \mathrm{keV}$ which confirmed the reduction of silver ions $\mathrm{Ag}+$ into $\mathrm{Ag}^{\circ}$ [49].

\section{CONCLUSION}

Many plants are becoming probable sources for reducing and stabilizing agents for the green synthesis of AgNPs. The constituents present in the plant cover the biomolecules that are naturally present in the plants. AgNPs have shown great attention because of their unusual physical, chemical, electronic, magnetic, antibacterial, and biological activities. The physical and chemical methods which are used for the synthesis of AgNPs have been followed over decades. The use of expensive procedures and various toxic chemicals in their synthesis makes the biological synthesis the more preferred alternative. Results of several studies indicated that the synthesized AgNPs by the plants have got more stability in comparison with those produced by the microorganisms and other methods as they are environment-friendly, cost-effective and is devoid of any complicated process of maintaining the cell cultures.

\section{AUTHOR'S CONTRIBUTION}

Dr Amit Chattree has provided the idea of designing the protocol and the individual content for writing the review along with the mentorship.

Shyla Haqq has majorly performed the experiment, analyzed the obtained data and sincerely authored the article. 


\section{CONFLICTS OF INTEREST}

The authors declare that there are no conflicts of interest regarding the publication of the article.

\section{REFERENCES}

1. Wijnhoven SW, Peijnenburg WJ, Herberts CA, Hagens WI, Oomen AG, Heugens EH, et al. Nanosilver-a review of available data and knowledge gaps in human and environmental risk assessment. Nanotoxicology 2009;3:109-38.

2. Tran HQ, Nguyen QV, Le TA. Silver nanoparticles: Synthesis, properties, toxicology, applications and perspectives. Adv Nat Sci Nanosci Nanotechnol 2013;4:1-20.

3. Ahmad A, Mukherjee P, Senapati S, Mandal D, Khan MI, Kumar R, et al. Extracellular biosynthesis of silver nanoparticles using the fungus Fusarium oxysporum. Coll Surf B Biointerf 2003;28:313-8.

4. Kalishwaralal K, Deepak V, Pandian RK, Barathmani SM, Kartikeyan KS, Gurunathan BS. Biosynthesis of silver and gold nanoparticles using Brevibacterium Casei. Coll Surf B Biointerf 2010;77:257-62.

5. Ahmed S, Ahmad MS, Swami LS, Ikram S. Green synthesis of silver nanoparticles using Azadirachta indica aqueous leaf extract. J Radiat Res Appl Sci 2016;9:1-7.

6. Mittal J, Batra A, Singh A, Sharma MM. Phytofabrication of nanoparticles through plant as nanofactories. Adv Nat Sci Nanosci Nanotechnol 2014;5:1-10.

7. Hariprasad S, Santhosh KJ, Sravani D, Ravi KG, Madhu C, Susheela BG. Green synthesis, characterization and antimicrobial activity of silver nanoparticles. Int J Eng Res Appl 2015;5:30-4.

8. Krithiga J, Briget MM. Synthesis of silvernanoparticles of Momordica charantia leaf extract, characterization and antimicrobial activity. Pharm Anal Acta 2015;6:1-7.

9. Tiwari D, Behari J, Sen P. Application of nanoparticles in waste water treatment. World Appl Sci J 2008;3:417-33.

10. Mehata MS, Majumder M, Mallik B, Ohta N. External electric field effects on optical property and exotation dynamics of capped Cds Quantum dots embedded in a polymer film. J Phys Chem C 2010;114:594-601

11. Parvathy S, Vidhya K, Evanjelene KV, Venkatraman RB. Green synthesis of silver nanoparticles using Albizia Lebbeck (L) Benth extract and evaluation of its antimicrobial activity. Int J Innov Res Sci Eng 2013;2:1-5.

12. Savithramma N, Rao LM, Rao LM, Rukmini K, Devi SP. Antimicrobial activity of silver nanoparticles synthesized by using medicinal plants. Int J Chem Tech Res 2011;3:1394-402.

13. Obaid AY, Al-Thabaiti SA, Al-Harbi LM, Khan Z. Extracellular biosynthesis of silver nanoparticles. Glob Adv Res J Microbiol 2015;3:119-26.

14. Mulvaney P. Surface plasmon spectroscopy of nanosized metal particles. Langmuir 1996;12:788-800.

15. Haiss W, Thanh KT, Aveyard J, Fernig GD. Determination of size and concentration of gold nanoparticles from UV-Visible spectra. Anal Chem 2007;79:4215-21

16. Verma A, Mehata SM. Controllable synthesis of silver nanoparticles using neem leaves and their antimicrobial activity. J Radiat Res Appl Sci 2016;9:109-15.

17. Bagherzade G, Tavakoli MM, Namaei HM. Green synthesis of silver nanoparticles using aqueous extract of saffron (Crocus sativus L) wastages and its antibacterial activity against six bacteria. Asian Pac J Trop Biomed 2017; 7:227-33.

18. Paosen S, Saising J, Septama WA, Voravuthikunchai PS. Green synthesis of silver nanoparticles using plants from Myrtaceae family and characterization of their antibacterial activity. Mater Lett 2017;209:201-6.

19. Gomathi M, Rajkumar VP, Prakasam A, Ravichandran K. Green synthesis of silver nanoparticles using Datura stramonium leaf extract and assessment of their antibacterial activity. Resour Effic Technol 2017;3:280-4.

20. Surya S, Kumar DG, Rajakumar R. Green synthesis of silver nanoparticles from the flower extract of Hibiscus rosa-sinensis and its antibacterial activity. Int J Innov Res Sci Eng Technol 2016;5:5242-7.

21. Padalia H, Moteriya P, Chanda S. Green synthesis of silver nanoparticles from marigold flower and its synergistic antimicrobial potential. Arab J Chem 2015;8:732-41.

22. Vinay SP, Chandrasekhar N. Characterization and green synthesis of silver nanoparticles from Plumeria leave extracts. Study of their antibacterial activity. IOSR J Appl Chem 2017;10:57-63.
23. Indhumathy J, Gurupavithra S, Ravishankar K, Chitra JA. Green synthesis of silver nanoparticles using Cassia Fistula leaf extract and its applications. Mintage J Pharm Med Sci 2014;3:20-5.

24. Carmona RE, Benito N, Plaza T, Reciosanchez G. Green synthesis of silver nanoparticles by using leaf extracts from the endemic Buddleja globosa hope. Green Chem Lett Rev 2017;10:250-6.

25. Devaraj P, Kumari P, Aarti C, Renganathan A. Synthesis and characterization of silver nanoparticles using cannonball leaves and their cytotoxic activity against MCF-7 cell line. J Nanotechnol 2013;2013:1-5.

26. Anandalakshmi K, Venugobal J, Ramasamy V. Characterization of silver nanoparticles by green synthesis method using Pedalium murex leaf extract and their antibacterial activity. Appl Nanosci 2016;6:399-408.

27. Inbathamizh L, Mary EJ. Green synthesis and characterization of nano silver using leaf extract of Morinda pubescens. Asian J Pharm Clin Res 2012;5:159-62

28. Mohamed HN, Ismail AM, Mageed AM, Shoreit MA. Antimicrobial activity of latex silver nanoparticles using Calotropis procera. Asian Pac J Trop Biomed 2014;4:876-83.

29. Arokiyaraj S, Arasu VM, Kim HY. Rapid green synthesis of silver nanoparticles from Chrysanthemum indicum $\mathrm{L}$ and its antibacterial and cytotoxic effects: An in vitro study. Int J Nanomed 2014;9:379-88.

30. Is F. Green synthesis of silver nanoparticles using extract of Parkia speciosa Hassk pods assisted by microwave irradiation. J Adv Res 2016;7:961-9.

31. Khalil MM, Ismail EH, Ismail EH, El-Baghdady KZ, Mohamed D. Green synthesis of silver nanoparticles using olive leaf extract and its antibacterial activity. Arab J Chem 2014;7:1131-9.

32. Ponarulselvam S, Panneerselvam C, Murugan K, Aaarthi N, Kalimuthu K, Thangamani S. Synthesis of silver nanoparticles using leaves of Catharanthus roseus Linn. G Don and their antiplasmodial activities. Asian Pac J Trop Biomed 2012;2:574-80.

33. Rao B, Tang CR. Green synthesis of silver nanoparticles with antibacterial activities using aqueous Eriobotrya japonica leaf extract. Adv Nat Sci Nanosci Nanotechnol 2017;8:1-8.

34. Ahmad N, Sharma S. Green synthesis of silver nanoparticles using the extract of Ananas Comosus. Green Sustain Chem 2012;2:141-7.

35. Lakshmanan G, Sathiyaseelan A, Kalaichelvan PT, Murugesan K. Plant-mediated synthesis of silver nanoparticles using the fruit extract of Cleome viscose L: Assessment of their antibacterial and anticancer activity. Karbala Int J Mod Sci 2018;4:61-8.

36. Ojha S, Sett A, Bora U. Green synthesis of silver nanoparticles by Ricinus communis var carmencita leaf extract and its antibacterial study. Adv Nat Sci Nanosci Nanotechnol 2017;8:1-8.

37. Singh A, Sharma B, Deswal R. Green silver nanoparticles from novel Brassicaceae cultivars with enhanced antimicrobial potential than earlier reported Brassicaceae members. J Trace Elements Med Biol 2018;47:1-11.

38. Paulkumar K, Gnanajobitha G, Vanaja M, Pavunraj M, Annadurai G. Green synthesis of silver nanoparticles and silver based chitosan bionanocomposite using stem extract of Saccharum officinarium and assessment of its antibacterial activity. Adv Nat Sci Nanosci Nanotechnol 2017;8:1-9.

39. Padman AJ, Henderson J, Hodgson S, Rahman PK. Biomediated synthesis of silver nanoparticles using Exiguobacterium mexicanum. Biotechnol Lett 2014;36:2079-84.

40. Banerjee P, Satapathy M, Mukhopahayay A, Das R. Leaf extract mediated green synthesis of silver nanoparticles from widely available Indian plants: Synthesis, characterization, antimicrobial property and toxicity analysis. Bioresour Bioprocessing 2014;1:1-10.

41. Fouad H, Hongjie L, Yanmei D, Baoting Y, El-Shakh A, Abbas G, Jianchu M. Synthesis and characterization of silver nanoparticles using Bacillus amylolique faciens and Bacillus subtilis to control filarial vector Culex pipiens pallens and its antimicrobial activity. Artific Cells Nanomed Biotechnol 2016;45:1-10.

42. Patil S, Sivaraj R, Rajiv P, Venckatish R, Seenivasan R. Green synthesis of silver nanoparticles from the leaf extract of Aegle Marmelos and evaluation of its antibacterial activity. Int $\mathrm{J}$ Pharm Pharm Sci 2015;7:169-73.

43. Ranjitham MA, Suja R, Caroling G, Tiwari S. In vitro evaluation of antioxidant, antimicrobial, anticancer activities and characterization of Brassica oleracea Var Bortrytis L synthesized silver nanoparticles. Int J Pharm Pharm Sci 2013;5:239-51.

44. Raut RW, Mendhulkar VD, Kashid SB. Photosensitized synthesis of silver nanoparticles using Withania Somnifera leaf powder and silver nitrate. J Photochem Photobiol B Biol 2014;132:45-55

45. Klueh U, Wagner V, Kelly S, Johnson A, Bryers JD. Efficacy of the 
silver coated fabric to prevent bacterial colonization and subsequent device based biofilm formation. J Biomed Mater Res Part B Appl Biomater 2000;53:621-31.

46. Rai M, Deshmukh S, Ingle A, Gadi A. Silver nanoparticles: The powerful nano weapon against multidrug resistant bacteria. J Appl Microbiol 2012;112:841-52.

47. Veerakumar K, Govindarajan M, Rajeswary M. Green synthesis of silver nanoparticles using Sida acuta (Malvaceae) leaf extract against
Culex quinquefasciatus, anopheles stephensi, and Aedes aegypti (Diptera: Culicidae). Parasitol Res 2013;112:4073-85.

48. Pandian N, Chidambaram S. Antimicrobial, cytotoxicity and anticancer activity of silver nanoparticles from Glycyrrhiza glabra. Int J Pharm Sci Res 2017;8:1633-41

49. Ali AZ, Yahya R, Sekaran DS, Puteh R. Green synthesis of silver nanoparticles using apple extract and its antibacterial activities. Adv Mater Sci Eng 2015;2015:1-6. 